\title{
UM ESTUDO CITOLÓGICO COMPARATIVO DE THALICTRUM E ILEX
}

Henry Wilhelm Jensen (")

A escolha dos gêneros Thaliclrum e Ilex como base para o presente estudo se deve à existência de uma condição citológica peculia: entre as suas espécies. Sob alguns aspectos, membros dêstes gêneros. na região leste dos Estados Unidos, representam extremos de duas linhã divergentes de evolução cromosômica comum à maior parte das forma: unissexuais das plantas superiores. Uma comparação destas duas ter. dências pode sugerir o que produziu sua diversidade e até certo porto estabelecer o significado de diversos fenômenos citológicos que parecen: ser produtos desta evolução.

Além da diversidade de comportamento citológico nos dois gêneros. igualmente importante é a semelhança de hábito sexual. Em ambos cહ gêneros se encontram formas perfeitas: muitas são polígamas e algumas são funcional ou morfològicamente bem dióicas. Assim, dentro de cada gênero existe uma série que constitue uma transição completa dos herma. froditas aos unissexuais. Por outras palavras, o hábito sexual dêstes dois grupos parece ser de origem comparativamente recente e nos pode explicar o que aconteceu em outros grupos que agora são estritamente unissexuais e dos quais as formas perfeitas e intermediárias há muito ternpo foram eliminadas. Naturalmente, o tempo envolvido é realmente enorme e o uso do têrmo recente deve bem excluir muito de que o homem. histórico se lembre ou que o horticultor rotule como uma introduçãc recente. Dos dois gêneros em investigação, Ilex parece ter atingido c estado unissexual antes de Thaliclrum: no primeiro, não se descreveram espécies que sejam hermafroditas inteiramente (sòmente indivíduos isolados aquí e alí dentre as espécies polígamas), enquanto algumas espécies de Thalicirum na Europa, na Ásia e na América são geralments hermafroditas. Entretanto, as espécies de Ilex estão longe de estab: lizadas sexualmente : e isto é evidente por exemplo no conhecido folktore do sul da "Appalachian region", segundo o qual plantas masculinas

i) Dean. Warren Wilson College, Swannanoa, North Carolina, U.S. A. 
de Ilev opaca produzem trutos quando muito velhas e também pela observação do autor de um macho da mesma espécie que produziu frutos cada vez em menor quantidade por vários anos após o seu transplante; êle é agora completamente masculino e a árvore feminina adjacente não produz pólen se bem que anteras abortivas estejam presentes na maioria das flôres.

O problema é, pois, de comparação. Seu valor não é ilimitado porque as observações se restringiram à microsporogênese e o autor não está preparado para admitir completa semelhança de comporta. mento em plantas masculinas e lemininas dos tipos unissexuais. Como se verificará no capítulo reservado à discussão dêste artigo, as formas aziáticas e européias do gênero Thaliclrum foram tratadas por Kuhn (5) e Langlet (6) de modo que abundante material existe enquanto, no conhecimento do autor, nenhuma profunda investigação foi publicada sôbre Ilex. Algumas formas de $/ l x$ da Flórida não estiveram ao alcance do autor: estas, de acôrdo $\mathrm{cm}$ as suas relações sistemáticas, devem constituir interessante material poro investiqação por alquem que sstejo mais favoràvelmente situado.

\section{MATERTAL, L MÉTODOS}

Pela coleta de material de Ilex decidua e I. womitoria dos ssé cines do jardim botânico da Universidade de North Carolina em Orapel Hill, o autor agradece do jor. Lindsay S. Olive. Agradece também à Academia de Cjências de North Carolina pela contribuição de une parte da bolsa de estudos de 1942 da A.A.A.S. para esta investigasa A Srta. Iscibel Miller forneceu gentilmente inaterial de Thalictrum divirum de Hol Springs, em North Carolina.

Com as excecôes acma especiticadas, o material foi coletadc us município de Buncombe en North Carolina, a maior parte na áres de Swamanoa Valley. A preservaçäo foi feita em fluido de Camoy ou numa modificaça melhorada dester cuja fórmula o autor não pode revelar no momento por pertencer a outro laboratório. O material toi entac mcluido em nitrocelulose quente de acôrdo com a técnica desenvolvida por E. C. Jeffrey (2), e colorido pela hematoxilina férrica de Haidenhair. Os desenhos foram feeitos sem o auxílio de câmara clara.

\section{TERMINOLOGIA}

Faremos treqùentemente o uso da palavra heterocromâsomio, à qual, um ou dois dos sequintes significados se adaptam: 
a) um cromosômio que difere em estrutura e comportamento do cromosômio que the corresponde fornecido pelo complemento de outrc: pai (talvez o companheiro sináptico).

b) um cromosômio que não segue o comportamento meiótico dos outros cromosômios no complemento.

\section{INVESTIGACÕES}

\section{THALICTRIM (LAVIT'.'L DC. (Britt.) (n=7) Hormafrodita}

A microsporogênese em Thalictrum clavatum é inteiramente normal. Os sete cromosômios meióticos reunem-se na placa metafásica para a divisão heterotípica (fig. 1) e subseqùentemente os cromatídeos dirigem-se simultâneamente para os polos do fuso (fig. 3). Os sete cromosômios podem ser contados outra vez durante a divisão homotípica (fig. 5), na qual há uma semelhante recularidade de comportamento. A tetrade usual se forma à conclusão da meióse: os microsporos mostram um desenvolvirnento normal e parecem ser estruturalmente perfeitos. Dos cromosômios, quatro parecem ser grandes, dois médios, e um algo menor que os restantes não é extrema a variação de tamanho.

\section{THALKTRI./I (ORI.KYI.U (Brit) Small $(\mathrm{n}=\mathbf{7 0 )}$ Dioist}

Também em Thalictrum curiariem a meióse é estritamente normal. O autor encontrou nesta espécie o mais alto número de cromosômios do gênero: no entanto ela vegeta a poucos metros de Th. claralum, que tem omenor número, básico, de sete. Os cromosômios de Th. coriacétum são tão numerosos que tendem a lormar blocos quando vistos de un: ângulo polar durante a metafase heterotípica. É impossível contá-los então (fia. 8). Durante a anatase (cedo on tarde) o mesmo acontece (figs. 7 e 10). Assim, o im da profase oferece a única oportunidade satisfatória para contagem. Cêrca de 70 cromosômios são observados. se bem que sejam romuns as associaçôes de dois ou mais cromosômios. Não se observani cromosômios atrazados nem precoces e em momentc nenhum há expulsão de cromatina ao citoplasma. A tetrade é usual os microsporos são perteitos.

\section{TH.HITTKI:H HOKCI.II L. $(\mathrm{n}=14)$ Hioid}

Thalictrum tioicum é uma espécie tetraplóide em que o númerc reduzido é catorze (fig. 11). Um cromosômio parece ser substancial. mente menor que os restantes. A não ser isso, parecem estar presentes dois grupos duplicados de cromosômios. A variação em tipo de cro. 
mosômio e conexão do fuso é bem demonstrada na fig. 12. São inteiramente normais as divisões homo- $\epsilon$ heterotípicas, e também o desenvolvimento do pólen.

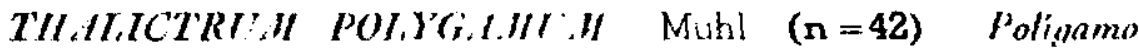

Uma investigação nesta espécie foi feita pela primeira vez pelo autor (8) quando parecia haver alguma razão para se acreditar que a condição polígama das fiôres devia indicar alguma irregularidade entre os cromosômios. Nenhuma foi encontrada então e nem depois. Esta espécie tem o número reduzido de 42 (fig. 16) e é inteiramente regular em tôdas as fases da meióse. Nenhum cromosômio se perde no citoplasma no fim da primeira jivisão (fị. 15) e quase todos os cromosômios parecem ter aproximadamente o mesmo tamanho.

Estas quatro escécies de Thalictrum que incluem os limites de variação em número de cromosômios $7,14,42$ e 70 até agora encontrados, são uniformemente regulares em comportamento meiótico. Além disso, não há diferença essencial no comportamento perfeito dos tipos polígamos ou dióicos.

\section{ESPÉCIES DE ILEX . PARTE GERAL}

Não é fácil a investigação das "hollier" americanas. Os cromosômios são muito pequenos, a coloração deve ser feita corn cuidado, e a diferenciação deve ser observada de perto. Os cromosômios têm uma tendência para se juntar na placa metafásica e como o fuso é comprido e muito estreito, os cromosômios raramente se dispersam suficientemente para que se possa fazer uma contagem segura. Ilex decidua é uma agradável exceção, pois que seus cromosômios se espalham durante a maior parte dos estados ativos. As profases são de difícil estudo, não só pelo reduzido tamanho dos núcleos como porque os cromosômios ficam ligados no que farece ser um espirema fundamentalmente contínuo, até o momento em que desaparece a membrana nuclear. A importância desta observação será discutida mais tarde. Omitimos os desenhos dos estados da meióse normal por julgarmos desnecessários.

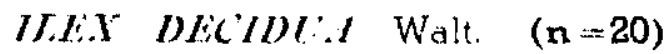

Uma vista polar da primeira divisão meiótica durante a microsporogênese"em Ilex decidua mostra vinte cromosômios, quatro dos quais são relativamente grandes e dois bem pequenos (fig. 18). Estes se arranjarn mais ou menos irregularmente pela placa durante a metafase. Em alguns cromosômios os cromatídeos separam-se mais ràpidamente 
que em outros e há uma tendêncio da parte de algumas unidades para ligar a parte associada dos cromatídeos através do centro da célula (fig. 17). A despeito da pesquisa pela evidência em contrário, todos os cromatídeos parecem se tornar parte dos núcleos filhos menhum traço de cromatina foi encontrado no citoplasma durante a telofase. Durante a segunda divisão (fig. 19), alguns "laggards" foram observados e alguns dêles expulsos do fuso e abandonados no citoplasma depois da segunda telofase (fig. 20). Entretanto, a julgar pelo tamanho da cromatina expulsa, sòmente um cromosômio parece ser suficientemente incompatível, o qual parece ser um cromosômio anafásico, da segunda divisão. Esste não é naturalmente o primeiro exemplo em que uma anormalidade meiótica não se apresenta na primeira divisão, mas é evidente na segunda.

A presença da cromatina expulsa limita-se a menos da metade das CMPs. se bem que alguns sacos polínicos mostrem irregularidades em quase tôdas as células enquanto em outros nenhuma célula dentro da secção contém cromosômio expulso. Uma tal variação extrema é também verificada em sacos polínicos adjacentes no mesmo filete.

\section{II.K. I HONTICOL.LI Gray $(\mathrm{n}=20)$}

Os cromosômios na primeira metafase em $I$. monticola são na maior parte aglomerados em uma massa compacta (fig. 21). Ocasionalmente, o número haplóide de 20 (fig. 26) nesta espécie pode ser distintamente contado em anafase. Nenhuma anormalidade ocorre até o fim de anafase, quando surgem alguns cromôsomios atrazados (fig. 22). Em cêrca de metade das CMPs. um dos cromatídeos-filhos do menor cromosômio é abandonado no citoplasma no fim da primeira divisão (fig. 23). Êste cromosômio parece ainda se dividir, mas apenas chega a atingir forma de alteres, parecida com a de um cromosômio normal durante o início de anafase. Durante a segunda divisão meiótica o pequeno cromatídeo é ainda visível (fig. 24). Incluimos a fig. 25 porque ela mostra o hete. rocromosômio no processo de divisão e possivelmente exibe também um estado excepcional da ocurrência de uma parte de um cromosômio no fuso de uma outra figura de divisão: nota-se que é um fragmento muito pequeno que fica no centro de um fuso anafásico e que se assemeIha ao pedaço do heterocromosômio em forma de alteres, que tem apenas três seç̧ões. Podemos resumir a condição citológica nesta espécie dizendo que a irregularidade se restringe a um heterocromosômio que se perde e degenera no citoplasma. No citoplasma dos microsporos não se encontra nenhum vestígio daquêle singular fedaço de cromatina; 
aparentemente êle é absorvido no início da formação de tetrade. O pólen parece ser bastante normal, existindo, porém, uma diferença na velocidade de desenvolvimento. Cêrca de metade dos microsporos se colore muito mais profundamente que os restantes. Nos estados iniciais de crescimento, nota-se também uma diferença em densidade do cito. plasma e a percentagem é aproximadamente a mesma. Entretanto, nâo há micronúcleos no material estudado e também pärece não haver grãos de pólen abortivos: nesse material o pólen estava pràticamente maduro.

\section{IISX OPACA Ait (n=18)}

Dos dezoito cromosômios meióticos de Ilex opaca (fig. 29) seis são bern grandes, onze são de tamanhio médio variável e um é distintamente pequeno. Um heterocromosômio é presente: êle parece ser precoce em relação à divisão, pois quo, frequentemente, se divide duas vêzes durante a primeira divisão mejótica. Entretanto, êste cromosômio dé tamanho médio se atraza en relação ao movimento no fuso e pode ser visto na placa equatorial quardo os cromosômios restantes já atingiram os polos. Todo êle ou una fna parte é abandonada no citoplasma no tim da primeira divisão em cêrce de $50 \%$ das CMPs. Durante a secunda divisão meiótica nada parece accntecer à cromatina expulsa até a tor. mação de tetrade, quando ela desaparece no citoplasma. Frequentemente o pedaço de cromatina a maíor parte das vêzes é apenas um pedaç permanece ao longo da parede celular e mesmo induz a parede blomação de una protuberância nesse lugar (fig. 31). O tamanho do heterocromosômio expulsc $\mathrm{f}^{2}$ a obstvaça do seu comportamento iniciat sugerem que, na maioria dos cascs, um dos dois cromatídeos-filhos da primeira divisão meiótica on inciudo nos grupos telofásicos de cromo:ômios da primeira divisão na se lon par parte de um grupo mitótico durante. a seounda divisão. Os cromatídecs restantes iniciam e às vêzes comple. tam una segunda divisão durante a parte final da primeira e regular divisão meiótica. Os cromatídeos filhos desta divisão não se separam inteiramente, mas reunem-sঞ en uma massa globular que jáz à periferia da célula onde degenera antes da citoqúnese.

É de algum interêsse a obstrvação de que durante a anafase hete. rotípica quatro dos maiores cromosômios são intimamente associados (fiạ. 28). Por ser de 20 o número reduzido de algumas outras espécies: de I/ex talvez êste fenômenc em Ilex opaca seja mais uma evidência de que o número básico para o gênero tenha sido de cinco em outros tempos, se bem que num passado remoto, porque o resto dos cromosômios 
não parece cair em qualquer de tais agrupamentos, e há sòmente um cromo:ômio muito pequeno.

Em Ilex opaca a anormalidade meiótica em cêrca de $50 \%$ das CMPs. é o aparecimento de um heterocromosômio, metade do qual é geralmente expulsa para o citoplasma, onde degenera. $\bigcirc$ pólen é altamente regular, se bem que se encontrem alguns grãos abortivos.

\section{ILEX VIRTICILLLITA (L.) Gray $(\mathrm{n}=18)$}

Os cromosômios meióticos de $\boldsymbol{I}$. verticillala são interessantes por causa do seu número e da presença de mais de um heterocromosômio. É particularmert 3 difícil o estudo dos cromosômios nesta espécie por causa de sua aglomeração e porque as velhas conexões de espirema freqùentemente aparecern ainda no início da anafase de modo que mesmo sob uma vista polar, diversos cromosômios se acham inter-ligados. Parecem ser 18 cromosômios. A fig. 32 representa uma das metaf́as ss mais normais encontradas, e foi ampliada na fig. 36 para mostrar a natureza do único cromosômio, o qual é muito menor do que qualquer outro do complemento. Além disso, êste tão pequeno cromosômio parece ser tricartido e quando é expulso do fuso, um maior e um menor pedaços de cromatina são encontrados freqùentemente próximos um do outro (fił. 34). Estretanto, metade de um cromosômio de tamanho médio também carec $\mathrm{s} \Leftarrow \mathrm{r}$ indesejável oos complementos-filhos, e êle também jáz no citonlasma em aproximadamente metade das CMPs. no fim da primeira divisão meiótica. A fig. 33 mostra uma anafase normal sem qualquər cromati:a "atrazada" ou expulsa. A fig. 37 é uma vista polar da metafase həterotípica e mostra 16 cromosômios livres---note-se que um dêles é muito pequeno -... e dois que são ligados por uma parte do velho esrirema.

A cromati :a expulsa parece degenerar logo nesta espécie, não se enco :tra ado d’.d qualquer traço nas fiłuras də segunda divisão. Natu. ralme te o material deve se incluir de novo nas figuras homotípicas. Os cromosômios são muito pequəàn, enovelados durante esta divisão, para serem os tados com suficiente exatidão de modo a determinar se a cromati la ex ứiz é ainda ausente ou restabelecida. Os microsporos parəcəm pasiar por um dəsənvolvim ənto normal, porém em cêrca de metade dos ros de pólen há uma co xcentração mais rápida do protoplasma do qu :os outros. Pode haver ou não qualquer significado para esta obsirvação.

Dever os ros lembrar que um cromosômio notàvelmente pequeno amkém tor "u trado em Ilex decidua e I. opaca, mas nestas espécies 
êle se comportara normalmente. Em I. rerlicillata. entretanto, o pequeno cromosômio é também heterocromático no comportamento e comumente tripartido em construção.

\section{ITIXY VO.HITORII Ait $(\mathrm{n}=20)$}

O número reduzido de cromosômios em Ilex v'omitoria parece ser vinte (fig. 40) e inclue um cromosômio muito pequeno, cujo comportamento é normal nesta espécie. No material que tivemos às mãos, nenhuma cromatina expulsa foi encontrada durante a microsporogênese. A segunda divisão é inteiramente normal; não se encontram microsporos abortivos. A peculiaridade desta espécie é quanto a um complexo tripartido que freqùentemente forma uma ponte através a anafase heterotípica inicial (fig. 38), a qual persiste ocasionalmente rnesmo até o fim da anafase (fig. 39). Nem todos os cromosômios se encontram no equador durante a metafase (fig. 41); entre os esparsos pelo fuso podem ser freqùentemente encontrados dois tipos: um é da forma usual e o outro é o complexo tripartido (fig. 43). Se bem que a segunda divisão seja bastante regular nesta espécie, os cromosômios são muito pequenos, agregados, para se contar com certo grau de exatidão. Se isso não acontecesse, seria possível traçar a disposição do cromosômio tripartido -... para verificar se êle determinou o estabelecimento de dois complementos diversos, como aquêles que se diz existir em diversas espécies de Rumex. Naturalmente, contagens para confirmar ou não esta segregação foram feitas. Algumas delas realmente confirmaram-na, outras confundiram-na. Não há seguramente base para uma opinião categórica ; o estudo poderia ser tentado por alguem que tivesse menos cuidado pela sua vista e mais imaginação do que o autor...

\section{DISCUSS $\widetilde{O} O$}

\section{Poliploidia e Aneuploidia}

Considerando apenas as espécies do leste americano, os gêneros Ilex c Thalictrum apresentam extremos de desenvolvimento citológico. $O$ primeiro é estritamente aneuplóide e dado à formação de heterocro. mosômios; o segundo é vastamente poliplóide, extremamente regulai en comportamento meiótico. Ambas condições são agora geralmente encaradas como tendo sua origem em hibridação prévia no grupo. Particularmente, quanto à poliploidia é êsse o caso. Kuhn (5) chegou a essa conclusão após o estudo do número de cromosômios de 37 espécies e formas de Thalictrum. Com poucas exceções, Inas 60 espécies e varie- 
dades investigadas por êle e Langlet (6) sòmente se estudaram figuras meióticas. Outro trabalho foi executado por Day (1) em Th. Fendleri e por Overton (7) em Th. purpuraicen.r, mas principalmente quanto à partenogênese, a qual, segundo Kuhn, não pôde ser bem estabelecida. Das 70 espécies reconhecidas por Engler-Diels, o número de cromosô. mios foi agora determinado para 63 formas, o que deve retratar o gênero com bastante exatidão. Onde a divisão de redução foi estudada, fala-se sempre da mesma regularidade de comportamento meiótico, e aquelas espécies incluem números reduzidos na seguinte série: $7,14,21,28$, 35, 42 e 70. Para Th. purpurarcen, Langlet determinou $\mathrm{n}=21$, mas Overton e Kuhn, separadamente, encontram aí uma exceção em que $\mathrm{n}=12$. A não ser êste caso, a espécie faz uma nítida série de 7 a 70 incluindo tanto espécies dióicas como perfeitas. As espécies com o número básico de 7 cromosômios não se restringem a uma dada região; assim, temos, por exemplo:

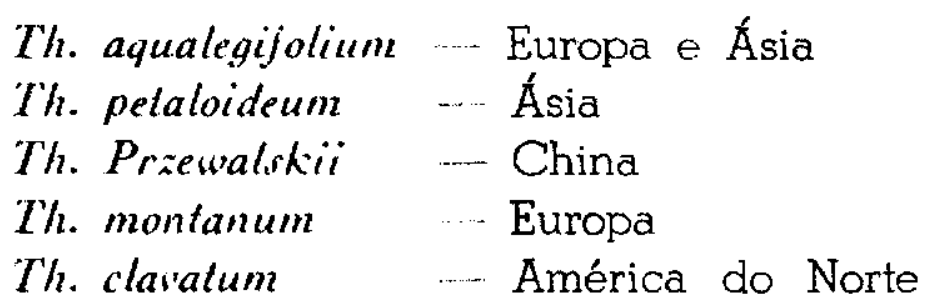

Os números mais altos distribuem-se também pelo hemisfério norte, mas se restringem largamente aos tipos dióicos. As formas perfeitas têm números haplóides de 7 a 21 , enquanto as unissexuais vão de 7 a 70 . Diferentes números são freqùentemente dados para a mesma espécie, mas em cada caso o número cai dentro da progressão. Aparentemente houve também poliploidia intra-específica. Não podemos concluir como no caso de Rumex -... Jensen (3) .... que a poliploidia tenha expandido as espécies perfeitas e que a secção dióica do gênero se tenha restringido a variações aneuplóides do número diplóide ou tetraplóide. Muito ao contrário, porque no caso de Thalictrum, os números mais altos encontram-se entre os tipos unissexuais. Outros gêneros que exibem semelhantes extremos de poliploidia são hermafroditas, e quase unânimemente os investigadores atribuem a multiplicação de complementos cromosômicos à hibridação prévia. Podemos, portanto, concluir, no exemplo de Thalictrum, que a hibridação foi responsável pela poliploidia e que, como alguns dos números mais altos são encontrados entre formas dióicas, a híbridação com conseqùente poliploidia ocorreu antes do advento da condição dióica.

O extremo oposto é encontrado ras espécies estudadas de Ilex : três espécies com 20 cromosômios meióticos e duas com 18. Em cada 
caso aparecem heterocromosômios entre as CMPs; além disso outros caraterísticos diagnósicos como cromosômios atrazados e precoces, cromatina expulsa, diferentes proporções de crescimento dos microsporos, lembram-nos do comportamento meiótico típico de híbridos. Esta condição é também bastante típica de um número de gêneros unissexuais que são aneuplóides e nos quais se descreveram heterocromosômios, como Smilax, Dioscorca e a seç̧ão dióica de Rumex. Devemos lembrar neste ponto que uma referência anterior foi feita à ausência em Ilex de espécies distintamente de llôres perfeitas, em contraste com a sud pre. sença em Thalictrum, com a conjetura que llax tomou a direção da unissexualidade antes de Thalictrum. No caso de Ilex é possíval que a hibridação da espécie tenha ocorrido simultâneamente ou depois do advento da condição dióica. Vamos admitir esta hipótese e ver que limitações seriam impostas pola simultâinea interação de duas forç̧as nuito elementares: hibridaça interespecífica e o estado unissexual.

Entre as plantas superiores hermafroditas o arranjo geral exize a maturação do fólen e do saco embrionário açoximadamente ao mesmo tempo na mesma planta, de modo que a autopolinização é mais variável que a polinização cruzada. Por assim dizer, não nos esquecemos das numerosas exceções em que a maturação de um tipo de esnoros é atrazada, ou a flor de tal modo construida, ou a espécie auto-estéril də modo que o que se dá é a polinização cruzada. Entretanto, a situação goral é perturbada quando uma raça de plantas começa a elimi de tecido esporogêrico das flôres num dado indivíduo. As probabilidades da ocorrência de autorolinização decrescem prozressivamente até que se estabeleça o estado funcional dióico. Cada ato de fertilização então envolve a introdução de protoplasma qua é até certo po to extranho à célula-ovo --, protoplasma de urn outro indivíduo, tâlvez da mesma raça, mas assim mesmo diferente, pois que não há dois indivíduss exatame ite iguais. Fôssem as esrécies genèticamente bem estabilizadas, o advanto da condição dióica não determinaria distúrbios no pronesso miótico; lembremos a êste respeito, da ceintena de plantas unissexuais que não

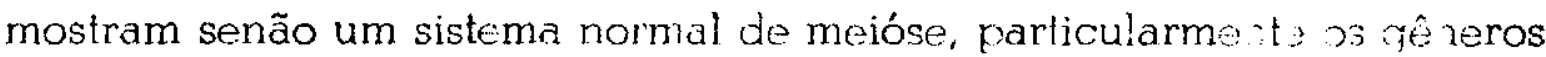
monotípicos, nos quais a única espécie não tem parente próximo com o qual se cruzar. Por outro lado, se as espécies afins e próxima admitirem polinização cruzada, deve ocorrer uma hibridação inter-ajućílca. Com ela vêm as irregularidades meióticas usuais : cromosôni j a recoces ou atrazados, distribuição desigual de cromosômios, núcloos e asoros múltiplos, esterilidade, etc. Subsequentemente cada ato da iertilização serve para reintrcauzir alguma coisa que descontrola o sist ma meiótico. Assim, geração afós geração, as plantas unissexuais se vão tor a ido 
genèticamente misturadas. Aparentemente estas formas unissexuais desenvolvem certo grau de tolerância, pois, do contrário, a desvantagem que levariam pela fertilidade decrescente devida à má distribuição, letal, dos cromosômios durante a meióse, determinaria sua graduả eljminação na competição com suas vizinhas hermafroditas. Com tôda probabilidade êste deve ser o caso, algumas vềzes. Entretanto, a persistência de numerosos tipos unissexuais por longos períodos de tempo sugere que é possível a existência de um certo grau de tolerância citológica. E, entretanto, esta mesma tolerânciá também não permite que acontega o que parece ser comum entre as plantas perfeitas: nestas, o distúrbio meiótico produzido pela hibridação é tão intenso que, em alguns casos, a divisão heterotipica se interrompe. Forma-se um núcleo de restituição, o número de cromosômios dobra, e assim se restauram a tertilidade e a meióse normal. Todavia, quando se descontrola o processo meiótion nas formas unissexuais, mas não tanto que dê para a formoção de anfidiploidia, haverá uma tendência para impedir a poliploidia e reter o número básico de cromosômios com uma lendência ainda para a diminuicão do número (aneuploidia negativa) pela exclusão de cromosômios de alçuns dos microsporos, exclusão essa que rão impede a formaçăo do tubo polínico e eventual tertilização.

Este parece ser o caso que ocorre com Ilex. O número básico do gênero parece ser 20 , e isto particularmente pelo fato da observação em Ilex opaca de 4 grandes cromosômios treqùentemente formando um quarteto o que talvez indique que, originalmente, o número básico era de 5 , o qual num perícdo de hibridaçạ̃o se elevou a 20 e mais recentemente diminuiu em algumas esfécies por um outro cerícdo de hibridação após o advento da condição dióica. Esste processor pode tes determinado o número $\mathrm{n}=18 \mathrm{em}$ Ilex opaca e I. ierficillala.

O esquema de incidentes acima delineado pareceria ser responsável pela diferença em topogratia cromosômica nos dois gêneros, Thalictrum - llea, os quais tomaram o hábito unissexual e sofreram hibridação. En vista das condições impostas por estes dois tatores modificadores e dos nossos conhecimentos da citologia dos híbridos, a diferença em épocas clana ao autor como uma hipótese firmemente alicerçada. No caso de Thalictrum, a hibridação deu-se antes, permitindo que se completasse um largo sistema poliplóide antes da mudança para a unissexualidade. No caso de Ilex, a hibridação ocorreu simultâneamente ou mesmo depois da ocorrência da unissexualidade.

Entre as plantas unissexuais encontra-se treqùentemente um terceiro grupo -.- constituido pelos gêneros em que as escécies são diplóides ou 
tetraplóides, como Populu, Salix, e a espécie dióica de Lychnir.. Talvez através de um estudo mais apurado dêste grupo em relação aos tipos extremos discutidos neste artigo se chegue a um ciclo completo. de fatos que abrangerá as várias formas produzidas pela interação da. hibridação e da diferenciação sexual.

\section{HETEROCROMOSONMIOS}

aparecimento de heterocromosômios em algumas CMPs. de tôdas as cinco espécies de llex em estudo, provàvelmente só tem impor. tância por fortalecer a opinião do autor de que serão encontrados heterocromosômios entre as espécies de qualquer grupo variável que simul. tâneamente caminhou para à hibridação e o hábito unissexual. Não é te surpreender que se encontrem vários tipos de heterocromosômios. Os seguintes foram encontrados em Ilex:
1. decidua
Um cromosômio de tamanho médio da segunda divisão meiótica ….. um cromatídeo expulso em cêrca de metade das CMPs. Degenera.

I. monlicola

O menor cromosômio do complemento

ums cromatídeo expulso durante a primeira divisãc. uneiótica. Degenera.

1. opaca … Um cromosômio atrazado, de tamanho médio um ou ambos cromatídeos-filhos expulsos durante a primeira divisão meiótica. Degenera.

I. rerticillata ... Um cromosômio muito pequeno, tripartido e atra. zado ... um cromosômio de tamanho médio tem umir cromatídeo-filho expulso em cêrca de metade das CMPs. A cromatina expulsa degenera.

I. imitoria … Dois tipos de heterocromosômio: um atrazado de tamanho médio, $e$ um tripartido do tipo de ponte anatásica. Não há expulsão de cromatina.

É interessante o complexo tripartido visto em algumas CMPs. if I. imitoria poraue pode representar um estado intermediário no desen. rolvimento do tipo mais notório de complexo tripartido encontrado nas CMPs. de algumas espécies "de Rumex. Neste último caso, sua presenço * seu comportamento têm sido interpretados como significativos de mtervenção ina determinação do sexo, e por essa razão êles têm sido 
encarados há bastante tempo como cromosômios sexuais. O autor re-investigou as formações de heterocromosômios em alguns dos casos clássicos em Rumex (3), sem chegar a uma conclusão tão taxativa. Há muitas razões para se acreditar que estes assim chamados cromosômios sexuais são tipos exatos de heterocromosômios, cuja origem está firmemente ligada à prévia hibridação, e cuja ocorrência é regulada pela determinação do sexo e não o sexo determinado pela presença dêste tipo especial de cromosômio. Uma atenção crescente à citologia das formas intermediárias entre os tipos estritamente dióicos e os perfeitos, e a admissão ao nosso pensamento de um mais amplo conhecimento do comportamento das plantas, devem corroborar com a opinião do autor sôbre êste assunto. A evidência da formação de heterocromosômios nas espécies de Ilex acima citadas é uma contribuição para êste fim. A variedade de comportamento heterocromosômico nestas cinco espécies é importante, pois ela indica porque existe tal diversidade entre os assim chamados cromosômios sexuais das espécies de Rumex e porque algumas das espécies não têm heterocromosômios. Seria difícil conceber como cromosômios sexuais que reaparecem com regularidade e têm um bem definido padrão de comportamento, podem surgir tão de repente. É mais razoável admitir que sejam necessárias várias gerações para o seu desenvolvimento, e se isso for verdade, a única fonte de "cromosômios do sexo" potenciais deve ser encontrada justamente entre tais tipos como as espécies de Ilex aquí descritas. Certamente o heterocromosômio tripartido em $I_{\text {. }}$ romitoria não tem uniformidade de comportamento e não se mostrou visível em metade das células estudadas: além disso não há confirmação de sua presença durante a mitose somática, mas o mesmo se dá em vários casos dos chamados "cromosômios sexuais". Por exemplo, a opinião se acha bem dividida quanto à existência de heterocromosômios em Rumex acetosella. Uma escola diz que há, outra insiste em que não há, e, no entanto, o autor viu células em que havia dois grupos. Quem está com a razão? Provàvelmente todos, dentro dos limites de suas observações. A variabilidade é certamente uma caraterística reconhecida nas plantas de origem híbrida e os cromosômios sexuais acham-se invariàvelmente associados com outros caraterísticos diagnósticos de hibridação. A medida que se obtiverem informações sôbre uma maior variedade de formas tornar-nos-emos capazes de traçar a evolução dos heterocromosômios com maior exatidão. Precisamos estudar mais tipos como Benzoin aertivale, Jensen (4), nos quais os heterocromosômios estão em processo de formação. Neste exemplo foi encontrado no macho um tipo X-Y de heterocromosômio. Fazemos 
agora apenas a sugestão de que os tipos de comportamento heterocromosômico em cinco espécies de: Ilex nos fornecem algumas irregularidades meióticas que parecem ser intermediárias entre os autosômios que se comportam normalmente $e$ os tipos especializarlos de heterocromosômios charnados cromosômios sexuais.

\section{A HEREDITARIEDADE DAS IRREGULARIDADES MEIÓTICAS}

A tendência geral para eliminar cromatina dos núcleos em cêrca de 50\% das CMPs de quatro espécies de Ilex em investigação apresenta uma base para esceculação. Se bem que os números aneuplóides de que se fez menção indiquem que alguma mudança afetou o número básico de cromosômios do đêtnero, há também forte indicação de que a mudança se operou mito vagarosamente e que num determinado período - número de cromosomios se tornou constante. Mas as anomalidades meióticas persistem um tipo de anormalidade que acarretaria a diminuição do número de clomosômios portanto, os microsporos que contêm os núcleos delicientes, em sua maior parte, não chegará a efetuar uma fertilização. F, assim: as CMPs. funcionais devem ser aquelas en que ocorre meióse normal. Isto é paradoxal, pois a anormalidade meiótica que aparentemente persiste durante muitas gerações se transmite através do tecido esporodênico que não manifesta o caráter. Como dissemos anteriormente. não há um comportanento uniforme em alguns sacos polínicos, tôdas as CMPs. contêm cromatina expulsa, em outros apenas a metade e finalmente noutros nenhuma apresenta cromatina expulsa. Não há uniformidade entre sacos adjacentes no mesmo estame. É possível que tôdas as CMPs. nestas espécies de Ilex sejam potencialmente anormais em comportamento meiótico, mas em alquns casos o distúrbio que faz aparecer o heterocromosômio é suprimido. Os estudiosos da citologia dos híbridos têm notado mais freqùentemente irregularidades menos pronunciadas na megasporogênese do que nas CMPs. em espécies hermafroditas en que a disposição genética deveria ser a mesma para ambos os tipos de tecidos esporogênicos. Aparentemente, - tecido envolvente pode atetar o comportamento interno de uma célula separada em alguns casos. O autor não se aventura a opinar mais que isto. A explicação para êste paradoxo talvez possa ser ericontrada pela extensão dos argumentos acima, mas, por enquanto, parece não ser aproveitável levar mais avante a cuestão. Deve servir somente para mostrar que todos aquêles que acreditam que os livros atuais de citologia já apresentaram ao mundo uma nítida explicação dos mistérios que nos confundem na vida celular, sào fàcilmente enganáveis e pouco curiosos. 


\section{SUMMARY}

1. New chromosome numbers have been determined tor the following spoies from naterial ollected in varsous ounties of Nonth Carolira, U.S.A.

\begin{tabular}{|c|c|c|}
\hline Thalidrum ctanalum & & $=$ \\
\hline Th. dioticesm & $n$ & $=$ \\
\hline Th. polygamum & $n$ & $=$ \\
\hline Th. remactum & $n$ & - \\
\hline Jlea decidtur & $n$ & - \\
\hline I. monticola & y & 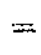 \\
\hline I. somitorat & $n$ & 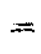 \\
\hline I. spataz & $n$ & $=$ \\
\hline 1. serticillater & $n$ & $\therefore$ \\
\hline
\end{tabular}

2. The genus Thatictrum has been rather well investigated cytologically but the genus Ilex has not yet received the attention it merits, and offers cytologists in North, Central, and South America an opportunily to study an extensive genus which has been, and probably is, undergoing interespecific hyinnization while a shift from the hermaphroditic to the unisexual habit is also well established. These two great evolutionary factors, hybridization and the advent of the dicecious condition, appear to stimulate divergent lines of meiotic behavior depending upon whether or not they appear in the phylogeny of a race simultaneously or successively, and in the case of the latter, which came iirst. The genus Thatictrum was used as a basis for comparison with the situation as found in the eastern North American forms of I/cw with the following conclusions.

a. The genus Thalictrum is vastly polyploid and meiotically regular. This condition is thought to be the result of previous hybridization of the species before the advent of the dioecious habit.

b. The genus Ilex 15 , as far as research has gone, negatively aneuploid and Irequently irregular meiotically. This condition is thought to be the result of previous hybridization of the species after, or no more than simultaneously with, the advent of the dioecious habit.

3. Heterochronosomes were found in microsporogeneris of all five species of Ilex, along with other meiotic peculiarities of suggested hybrid origin, but no two were alike. Behavior of the heterochromosomes was not found to be consistent and in approximately $50 \%$ of the PMCs. meiosis was normal. Findings are summarized in following table. 


\begin{tabular}{|c|c|c|c|c|}
\hline $\begin{array}{l}\text { Heterochromo } \\
\text { Species }\end{array}$ & $\begin{array}{l}\text { some Complex } \\
\text { Type of } \\
\text { Chromosome }\end{array}$ & $\begin{array}{l}\text { Divfsion in: } \\
\text { which first } \\
\text { seen. }\end{array}$ & $\begin{array}{l}\text { Chromatin } \\
\text { eiected. }\end{array}$ & $\begin{array}{l}\text { Other diagnostic } \\
\text { hybrid character. } \\
\text { istics. }\end{array}$ \\
\hline 1. decidua & Medium & Homeotypl: & $\begin{array}{l}\text { One chromatid } \\
\text { during second } \\
\text { anaphase. }\end{array}$ & $\begin{array}{l}\text { Laggards } \\
\text { anaphase bridges }\end{array}$ \\
\hline 1. monticola & $\begin{array}{l}\text { Smallest } \\
\text { member of } \\
\text { complement }\end{array}$ & $\begin{array}{l}\text { Hetero. } \\
\text { typic }\end{array}$ & $\begin{array}{l}\text { One chromatid } \\
\text { during first } \\
\text { anaphase. Left } \\
\text { in cytoplasm }\end{array}$ & $\begin{array}{l}\text { Lagging } \\
\text { Precocious chrou. }\end{array}$ \\
\hline I. opaca & Medium & $\begin{array}{l}\text { Heter } \\
\text { typin }\end{array}$ & $\begin{array}{l}\text { Whole chrom. } \\
\text { One chromatid } \\
\text { sometimes accept. } \\
\text { ed by complement } \\
\text { in second div. }\end{array}$ & Lagging chrom. \\
\hline I. verticillata & $\begin{array}{l}\text { Two types. } \\
\text { One triparite } \\
\mathrm{X}-\mathrm{X}_{1} \mathrm{Y}_{2} \text { small } \\
\text { Other medium }\end{array}$ & $\begin{array}{l}\text { Heters } \\
\text { typi: } \\
\text { Heter: } \\
\text { typu: }\end{array}$ & $\begin{array}{l}\text { Yes. Degenerates } \\
\text { during first telo- } \\
\text { phase. } \\
\text { Yes. Degenerates } \\
\text { during first telo- } \\
\text { phase. }\end{array}$ & \\
\hline I. ivomitoriat & $\begin{array}{l}\text { Medium sized } \\
\text { tripartite } \\
\text { complex }\end{array}$ & $\begin{array}{l}\text { Hetero } \\
\text { tyrio }\end{array}$ & None found & $\begin{array}{l}\text { A number of } \\
\text { laggards dur- } \\
\text { first division }\end{array}$ \\
\hline
\end{tabular}

4. In view of the generally stable chromosome number for the five species of $/ 1 \%:$ investigated, only such poller as arises trorr PMCs. which possess the normal rrevosi: may produce the gametes which effect fertilization. This presents the problem of expia: ning how the ability to produce meiotic abnormalities is inherited through cells whinh d. not exhibit it or through the female sirke and ins significance on the whole question of the evolution of sex chromosomes from: various ispes of heterochromosomes.

5. A comparison of the cytology of speses of Thatictrum and $/ 1 \mathrm{~h}$ adds suppor: to the author's earlier contention that wowlied sex chromosomes in higher plants have their origin in special types of heterochromosomes which in turn owe their appearance ic meiotic disturbances induced by previcus hybridization of the species and preserve: through the more or less simultaneous advent of the dicecious habit. In the author'; opinion, the genus Il'x offers an opportunity to increase our knowledge of what occus during the stage intermediate between autosone and the specialized types of sex-linke: heterockromosomes.

\section{LITERATURA CITADA}

1. Day, D.F. Parthenogenesis in Thalictrum Findleri Bot. Gaz. 22:41. 1896.

2. Jeffrey, E.C. Technical Contributions Bot. Gaz. 86:456-467. 1928.

3. Jensen, H.W. Meiosis in Rumer. II The origin and behavior of the so.calles sex-chromosomes in Rume.r. Cytologia 7:23-34. 1936. 
4. Jensen, H.W. Heterochromosome formation in Binsoin aestriale (L) Nees. Cytc logia 11:591.599 1941.

3. Kuhn, E. Zur Zytologie von Thalictrum. Jahr. wiss. Bot. 68:382-430 1928.

5. Langlet, O. Beitrage zur Zytologie der Ranunculazeen Sv. Bot. Tids. 21:1-17 1927.

7. Overton, J.B. Über Parthenogenesis bei Thalictrum purpurancent. Vorl. Mitt. Ber, d. Deutsch. Bot. Ges. $22: 274.2881904$.

8. Jensen, H.W. The Origin of Sex Chromoscmes in Higher Plants La Celluile. $48: 49.601939$.

\section{EXPLICAÇ̃̃O DAS FIGURAS}

\section{ESTAMPA I}

Figuras 1-6. Thalictrum clavatum. Microsporogênese.

Fig. I -... Vista lateral de metafase heterotípica

. 2 -... Vista polar de metafase heterotípica. $n=$.

. 3 -... Anafase heterotípica

. 4 -... Vista polar de anafase helerotípica

5 -... Vista polar de um complemento metafásico em divisăo homotípica

6 -.- Metafase da segunda divisão meiótica.

Figuras 7-10. Th. coriuccum. Microsporogênese.

Fig. 7 -- Metafase heterotípica. Note-se a uniformidade dos cromosômios

8 -.. Visla polar da mesma para mostrar o agripamento dos cromosônic:

9 -... Núcleo pre-meibtico para mostrar 70 crcmosômios em diagúnese

$\therefore 10 \ldots$ Anafase heterotípica

\section{ESTAMPA II}

Figuras 11.14. T. dioicum. Microsporogenese

Fig. 11 -... Metafase heterotípica. Vista polar, $n=14$

. 12 -. A mesma, vista polar, mostrando vários nipo: de cromosômios

. 13 -.. Anafase heterofípica

. 14 … Fim da segunda divisão meiótica.

Figuras 15-16. T. polygamum. Microsporogênese

Fig. 15 -. Anafase heterotípica

16 .... Contagem de cromosômios na divisãe heteroticica. $x=42$

ESTAMPA III

Figuras 17-20. Ilew dicidua. Microsporogênese

Fig. 17 - Metafase heterotípica. Vista laterai

„18 -... Metafase heterotípica. Vista polar. $\mathrm{n}=20$

19 -.- Segunda metafase meiótica mostrando expuisão de cromatina

.. 20 -.. Quarteto nuclear e degenerescência de cromatina no citoplasma.

Figuras 21-22. 1. monticola. Microsporogênese

Fig. 21 - Metafase heterotípica

" 22 -... Anafase da divisão heterotípica mostrando "laggards". 


\section{EGTAMFA IV}

Figuras 23-26. 1. monticola. Miomexpregênese

Fiạ. 23 … Telofase da I.: divisar, rom cromosomio expulso do aitoplasma

. 24 -... Metafase hornctínics

- 25 ... Anafase horrotipca motrando "laggard" e cromatina expulsa.

¿26 .... Metatase hetrotífica. Visia polar. $n=20$.

Figuras 27.29. I. opaca. Microponoterese

Fia. 27 Metafase heterolíph mostrando heterocromoschio

283 .... Vista polar de do tipa de conliguraşes anafásicas, umo das guas mostra guatro grandes comosômios associados

9 Vieta polar da divia du heretípica $n=18$

\section{ESTAMPA V}

Figuras 30.31. I. opaca. Micresporotênese

Fig. 30 -.. Anafase heterotipica mostrando cromatina expulsa

. 31 ..... Cromatina cin í visível no chtoplasma à telofase da 2." divisão

Figuras 32-35. 1. werticillat. Microsporcoênese

Fig. 32 -... Metafase heterotipica

- 33 … Anafase heterotipica. Coma regula:

- 34 -... Telofase da i." divisio mostrando romatina expulsa

. $35 \cdot 2$. divisa meibtica regular

\section{ESTAMPA VI}

Frauras 36-37. 1. Wricillala. Microsporogênese

Fia. 3i ... Metafase heterotipar. Vista leferal mostrando pequeno cromostruc precoce

- 37 -.... Metafase heterntificd Vista polar. $n=18$

Fơuras 38.43. I. .omitoria. Microspongênese

Fia. 38 ... Inicio de Anafase heterotipica mostrando ponte iripartida

39 -.. Estádic mâs avanģaro da mesmo

40 -... Metafase heterotipica Vista polin. $n=20$

4 i … Metatase heterotipica mostrando heterocromosomio singular

42 -... Tino normal de "iggard"

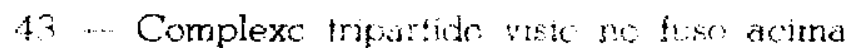



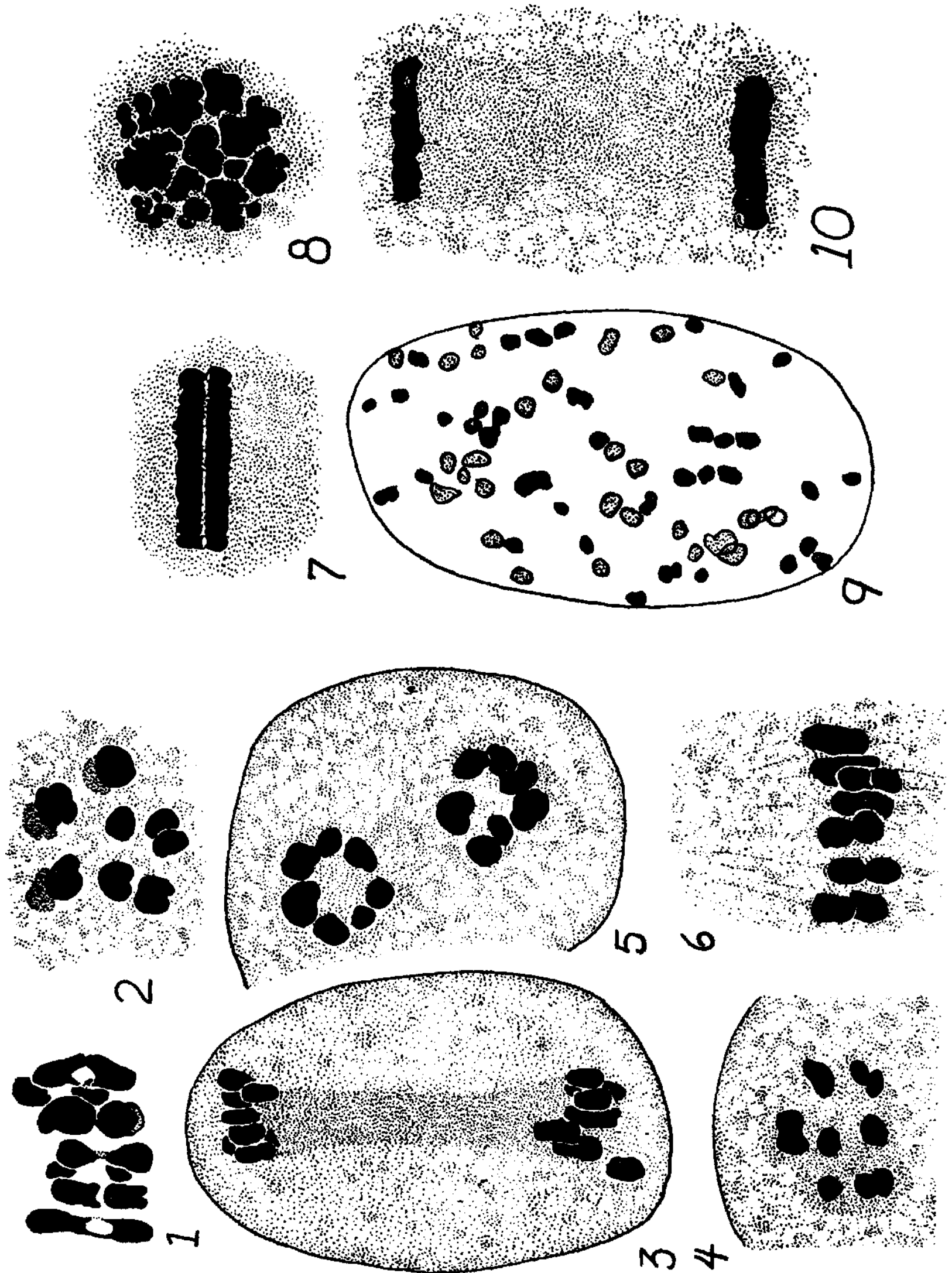
i.
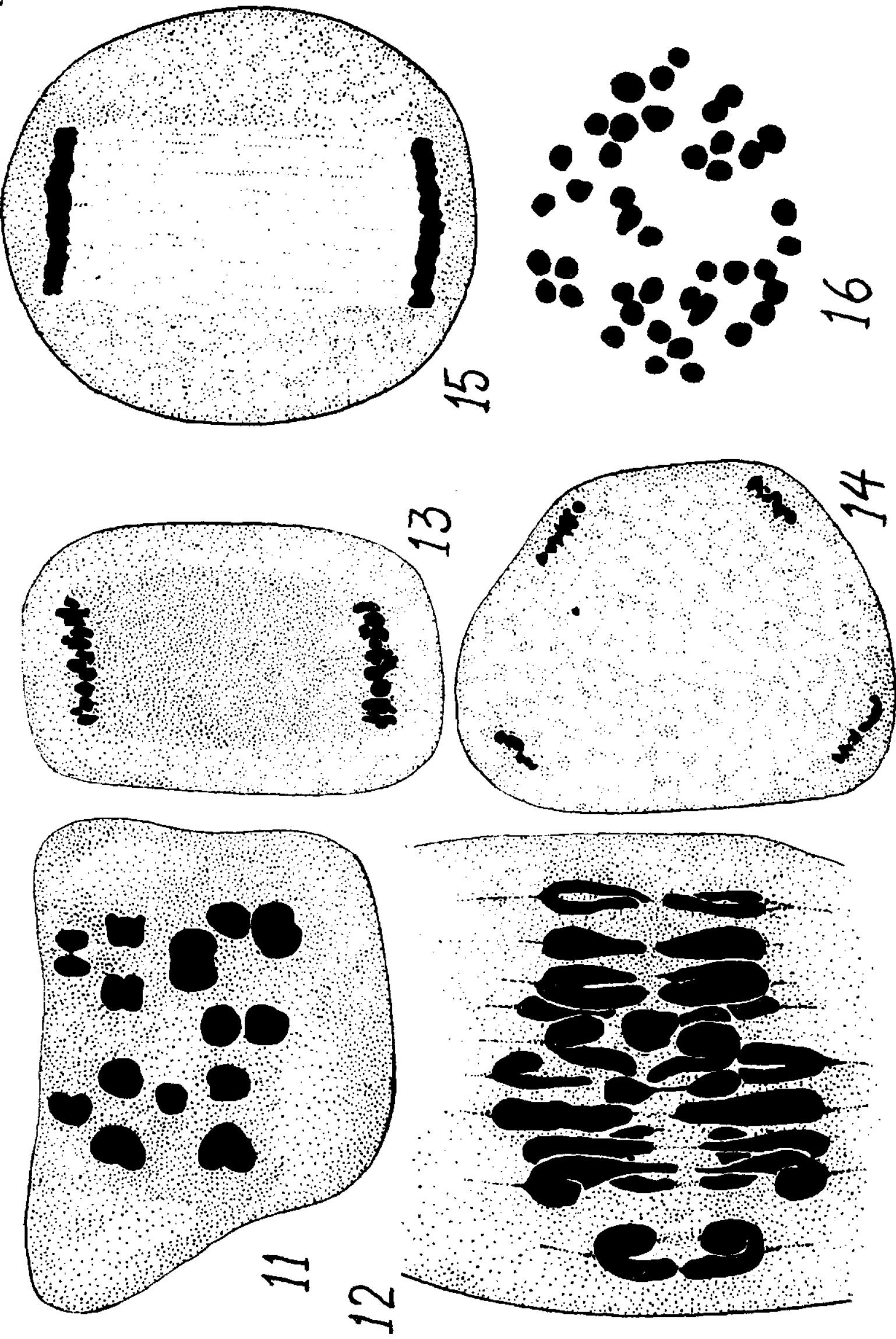

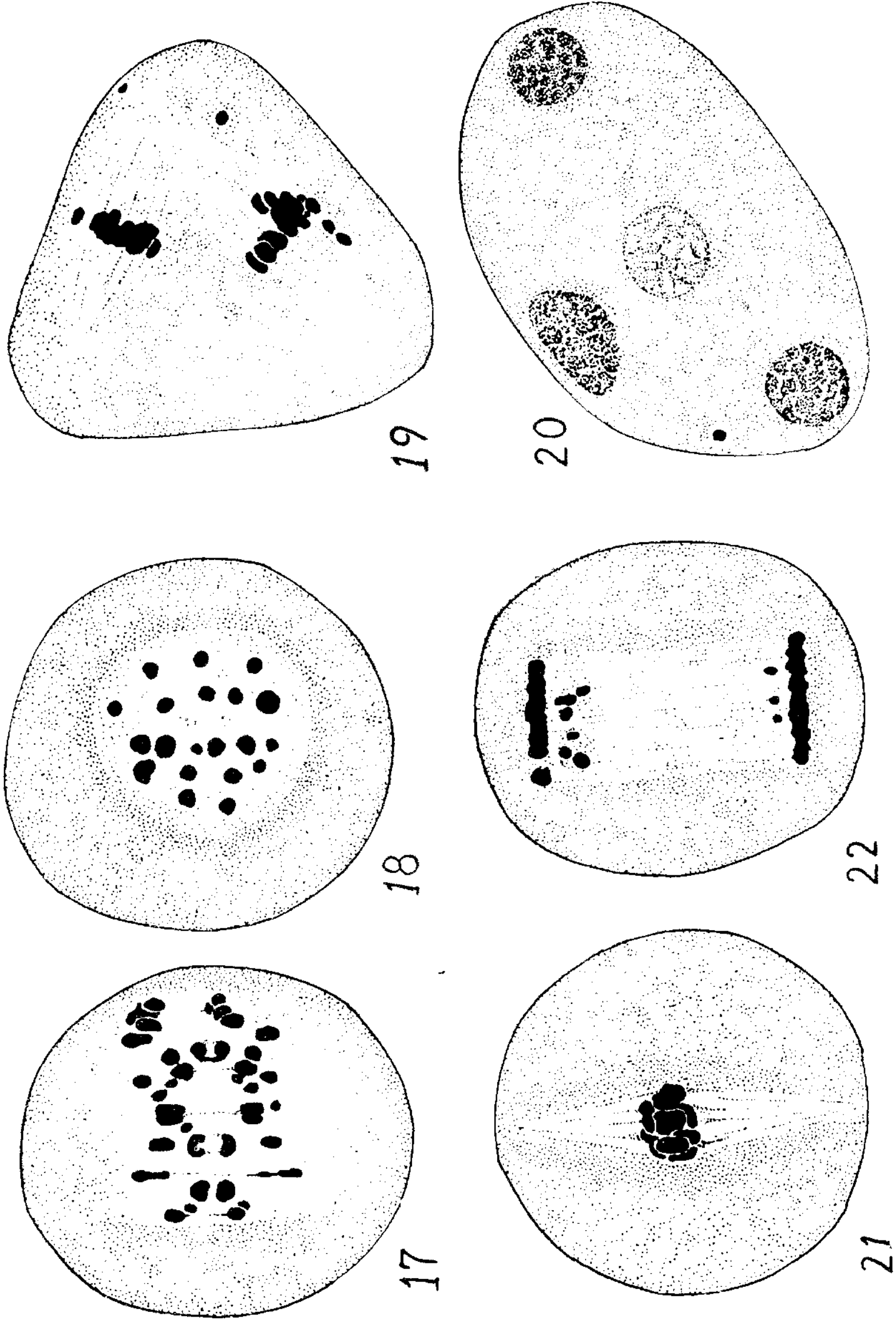

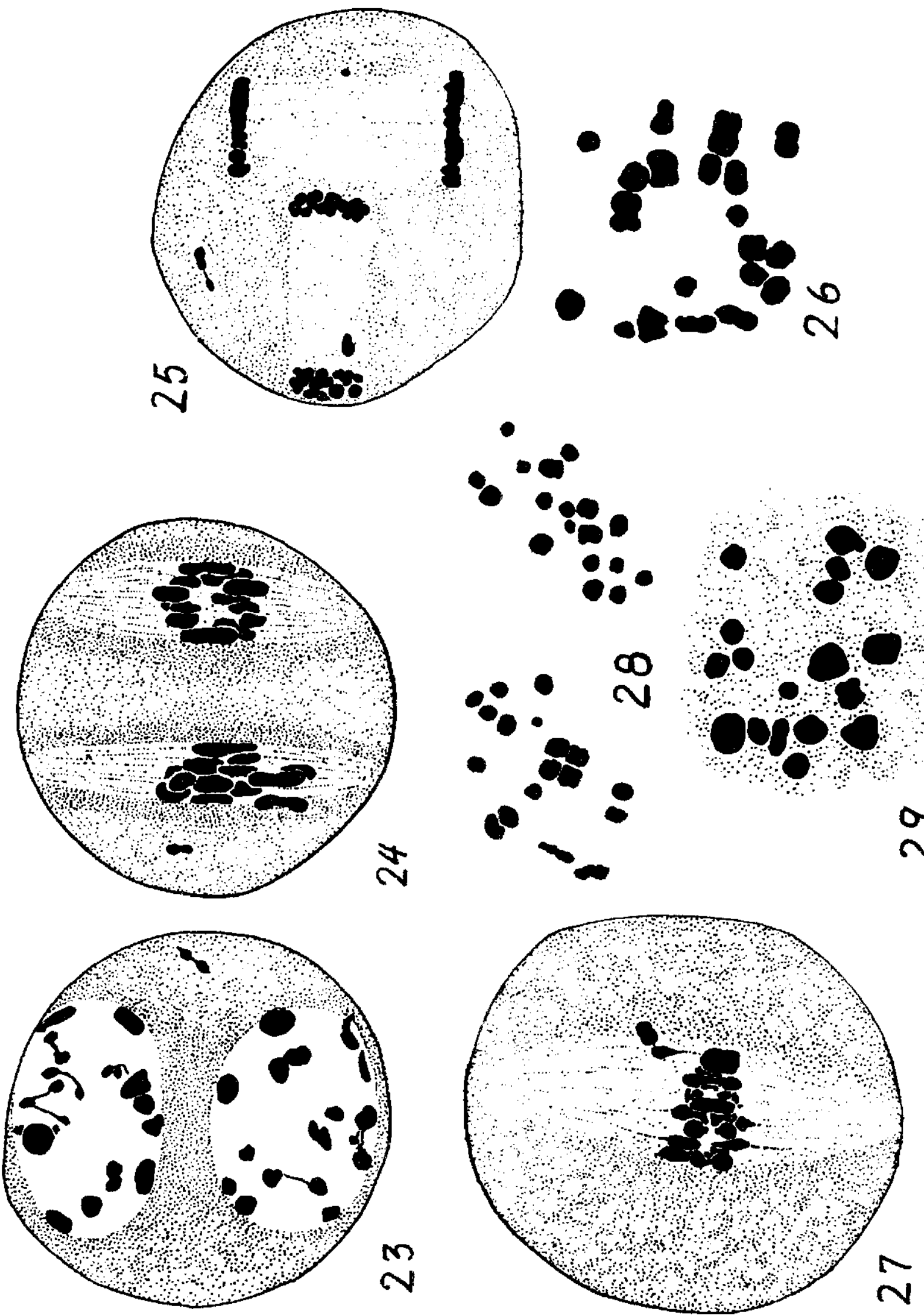

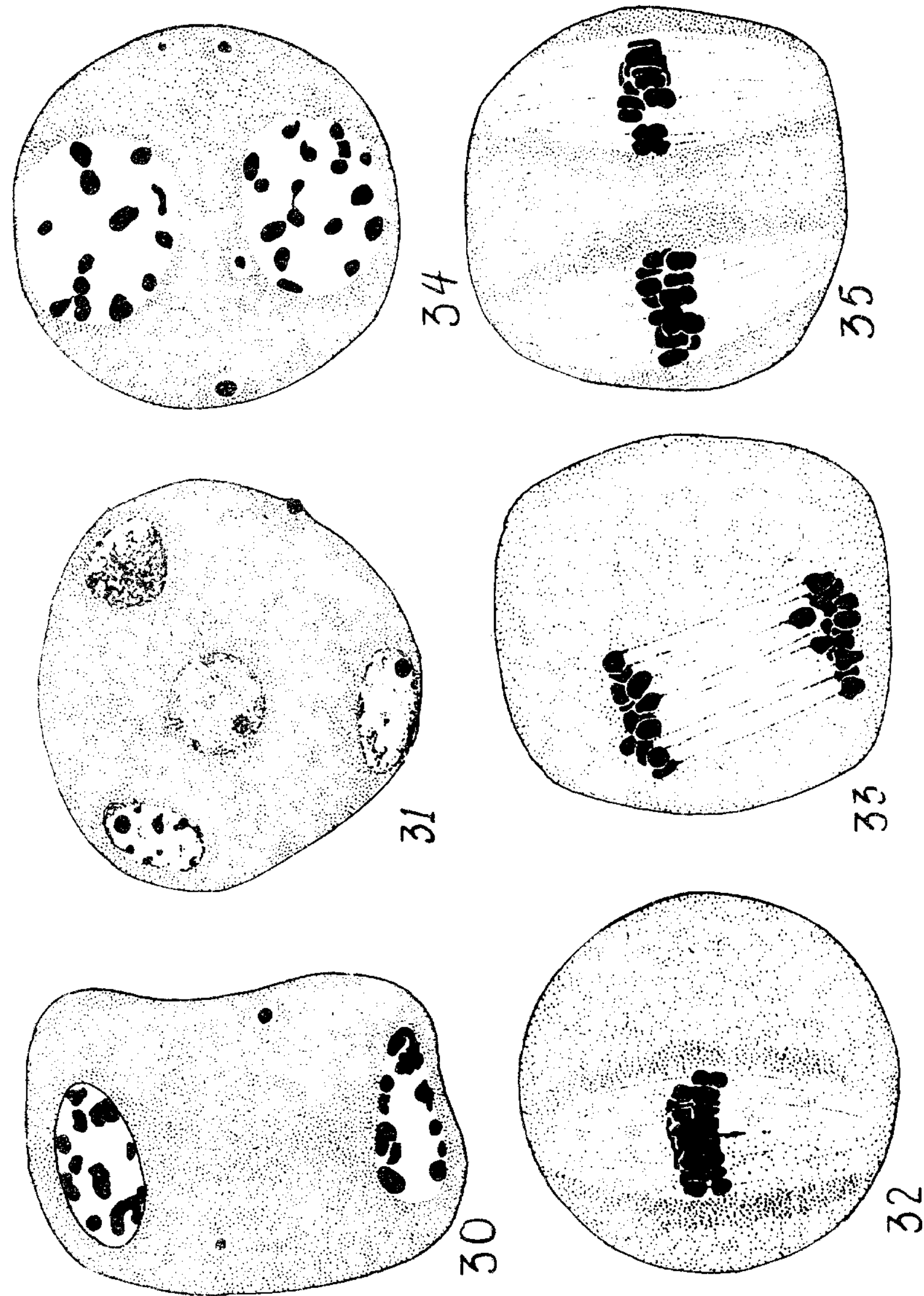

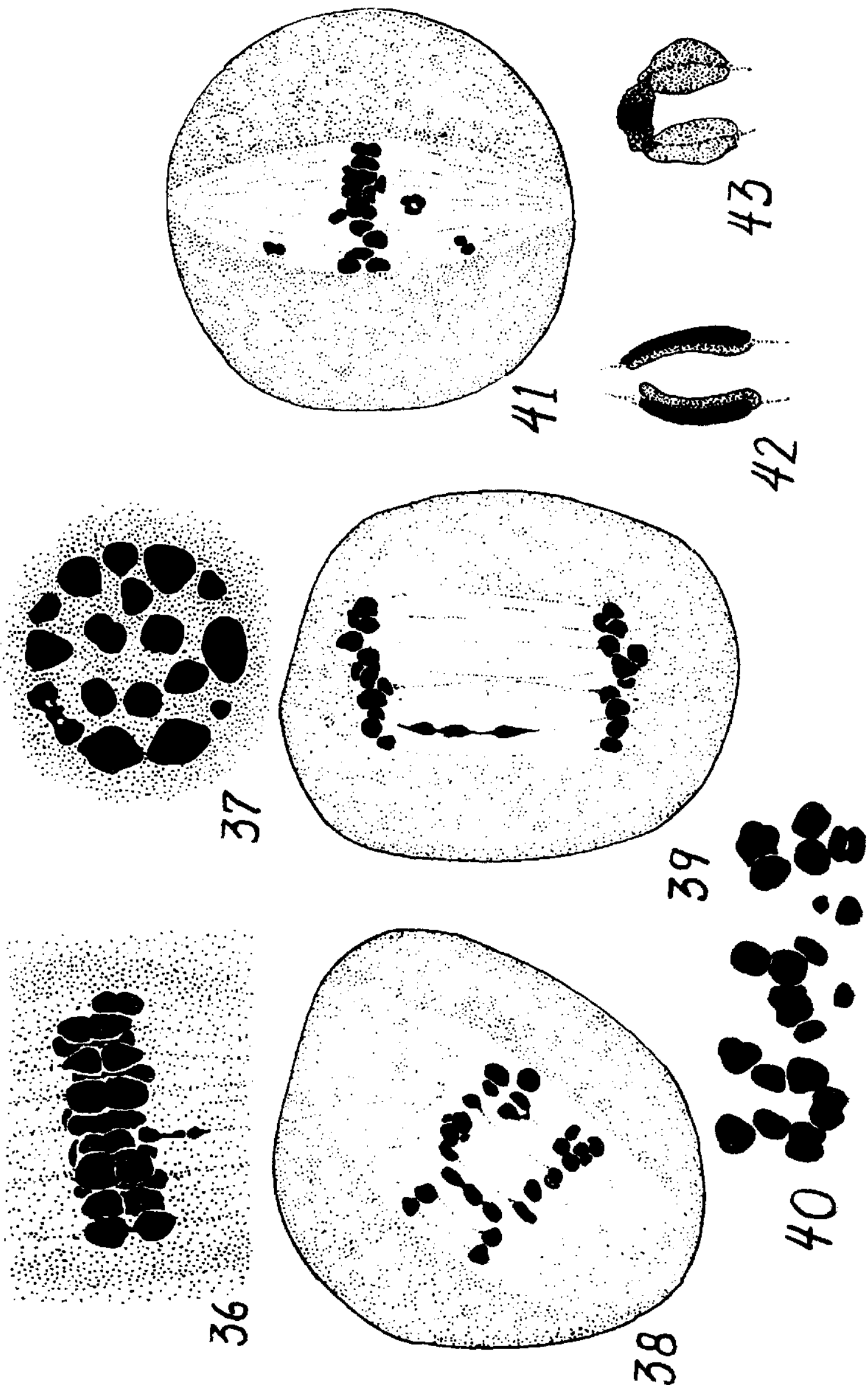